\title{
Erythrocyte Acetylcholinesterase Enzyme Activity, Serum Interleukin-6 Level and Respiratory Function of Myanmar Agricultural Workers Exposed to Organophosphate Pesticides
}

\author{
Thurein Zaw*, Mya Pwint Phyu, Sanda Kyaw
}

\section{Thurein Zaw*, Mya Pwint Phyu, Sanda Kyaw \\ Department of Physiology, University of Medicine-Magway, Magway, MYANMAR. \\ ${ }^{*}$ Correspondence \\ Dr. Thurein Zaw \\ Postal Address: University of Medicine - Magway, Natmauk Road, Magway, Township, Magway Regional Division, MYANMAR.}

Phone: +95-9-785344084

Email: drthureinzaw@gmail.com

\section{History}

- Submission Date: 19-07-2020;

- Review completed: 24-08-2020.

- Accepted Date: 11-09-2020.

DOI : 10.5530/ijcep.2020.7.3.26

Article Available online

http://www.ijcep.org

\section{Copyright}

(C) 2020 Phcog.Net. This is an openaccess article distributed under the terms of the Creative Commons Attribution 4.0 International license.

\begin{abstract}
Background and Aim: Myanmar is one of the countries in production of agricultural plant commodities. Nowadays, pesticides are commonly used to increase agricultural production and productivity. Organophosphate pesticides exposure can cause many physiological changes within the body including impaired respiratory function. Therefore, the present study aimed to find out the relationship between the erythrocyte acetylcholinesterase enzyme activity, serum interleukin-6 level and respiratory functions such as forced expiratory volume in first second (FEV1), forced vital capacity (FVC), ratio of forced expiratory volume in first second and forced vital capacity (FEV1/FVC), peak expiratory flow (PEF) and average forced expiratory flow between $25 \%$ and $75 \%$ of FVC (FEF25-75\%) among agricultural workers who exposed to organophosphate pesticides and non-exposed control subjects. Methods: A community-based cross-sectional, comparative study was done in agricultural workers ( $n=40$ ) who live in A-lal-chaung village, Magway Township and age/BMI matched non-exposed subjects ( $n=40$ ) who live in Yan-Way Quarter, Magway Township. All the participants were selected according to inclusion and exclusion criteria by simple random sampling method. Erythrocyte acetylcholinesterase (AchE) enzyme activity was measured by spectrophotometric method and serum interleukin-6 levels were measured by enzymelinked immunosorbent assay (ELISA) method. Respiratory function parameters were measured by Spirobank II spirometer. Results: The mean erythrocyte acetylcholinesterase enzyme activity was significantly lower in exposed group than that of non-exposed group $(3354.43 \pm 589.81 \mathrm{U} / \mathrm{L}$ vs $4515.83 \pm 759.33 \mathrm{U} / \mathrm{L} ; p<0.001)$. The percentage of predicted value of respiratory function parameters of exposed group were significantly lower than that of non-exposed group (FEV1: $72.13 \pm 4.40$ vs $75.95 \pm 4.05$; FVC: $66.90 \pm 4.40$ vs $70.60 \pm 4.20$; FEV1/FVC: $110.35 \pm 2.69$ vs 111.32 \pm 1.33 ; PEF: $5.52 \pm 8.66$ vs $79.40 \pm 5.09)(p<0.05)$. There were significant positive correlation between erythrocyte acetylcholinesterase activity and respiratory function parameters in all groups ( $n=80$ ) (FEV1: $r=0.425, p<0.001$; FVC: $r=0.301$, $p<0.05$ and PEF: $r=0.316, p<0.05)$. There were significant negative correlation between erythrocyte acetylcholinesterase activity and serum IL-6 level $(r=-0.374, n=80, p<0.05)$. Serum IL-6 level was significantly higher in exposed group than non-exposed group $134.77 \pm 3.3$ $\mathrm{pg} / \mathrm{mL}$ vs $28.75 \pm 2.0 \mathrm{pg} / \mathrm{mL} ; p<0.001)$. There was a significant negative correlation between serum IL-6 level and respiratory function parameters in all group $(n=80)$ such as FEV1 ( $r=$ $0.300, p<0.05)$ and FVC ( $r=0.331, p<0.05)$. Conclusion: It was concluded that agricultural workers who exposed to organophosphate pesticides have higher serum IL-6 level and lower respiratory functions than that of non-exposed subjects. The present findings highlighted that there has an impact of chronic low dose OP exposure on respiratory health and there has a role of IL-6 in respiratory function decline.
\end{abstract}

Key words: Acetylcholinesterase, Interleukin-6, Respiratory Function, Organophosphate Pesticides, Agricultural Workers.

\section{INTRODUCTION}

Nowadays, numerous environmental pollutants such as industrial waste, polluted air and chemicals including pesticides are continually exposed to living organism. Since Myanmar is one of the agricultural countries, the agricultural sector is the backbone of its economy. Therefore, increased farm production is an important factor for agricultural workers. At the same instant, agricultural workers are reliant on pesticides to raise farm productivity.

Pesticides include many different chemical compounds which have specific mechanisms of action. According to the different chemical structure, pesticides are classified as carbamates, coumarin derivatives, organophosphate compounds (OP), organochlorine compounds and pyrethroids. ${ }^{[1]}$

Among them, OP compounds are used as pesticides since $1854 .{ }^{[2]}$ In Myanmar, OP compounds are still widely used as pesticides in farm productivity. OP

Cite this article: Zaw T, Phyu MP, Kyaw S. Erythrocyte Acetylcholinesterase Enzyme Activity, Serum Interleukin-6 Level and Respiratory Function of Myanmar Agricultural Workers Exposed to Organophosphate Pesticides. Int J Clin Exp Physiol. 2020;7(3):107-11. 
compounds are acetylcholinesterase (AChE) inhibitors. After exposure to $\mathrm{OP}$ pesticides, they cause accumulation of acetylcholine $(\mathrm{ACh})$ in the body which binds to the nicotinic and muscarinic cholinergic receptors and results in toxic effects of OP pesticides. ${ }^{[3]}$

Many studies have been reported that OP pesticides have many toxicology effects on the body systems such as central nervous system, respiratory system, endocrine system, immune system, gastrointestinal system, cardiovascular system and genitourinary system. ${ }^{[4-6]}$ The clinical features of OP poisoning vary depend on acute or chronic duration and high-dose or low-dose exposure. Respiratory effects of highdose OP exposure include bronchoconstriction, pulmonary oedema and respiratory muscle paralysis. Short-term respiratory symptoms reported following acute low-dose exposure to OP include chest pain, cough, wheezing, difficulty in breathing, shortness of breath, runny nose and throat irritation. ${ }^{[7]}$ Many experimental studies showed that the respiratory function is reduced in subjects who have chronic exposure to OP pesticides when compared with non-exposed subjects. ${ }^{[8-11]}$

Moreover, OP pesticides exposure causes damaging effects on the immune system and secretes inflammatory mediators such as cytokines, chemokines, reactive oxygen species (ROS) and reactive nitrogen species (RNS). ${ }^{[12]}$ Shaaban et al. (2006) reported that inflammatory mediators such as interleukin-6 (IL-6) increases the hepatic production of $\mathrm{C}$-reactive protein (CRP), which causes lung parenchyma damage and pulmonary fibrosis leading to structural changes. This structural change narrows the airway and limits the air flow and resulting in respiratory function decline. ${ }^{[13]}$ Accordingly, it can be hypothesized that inflammatory mediator, IL-6 is tracing link between OP pesticide exposure and respiratory function decline. In view of this, the present study investigated the erythrocyte acetylcholine esterase enzyme activity and serum IL-6 levels for the chronic low-dose pesticide exposure and impact of chronic low dose of agricultural pesticide on the respiratory health of agricultural workers.

\section{MATERIALS AND METHODS}

\section{Subject Selection}

This community-based cross-sectional comparative study was undertaken in forty agricultural workers living in A-lal-Chaung Village, Magway Township who exposed to OP and forty non-exposed subjects living in Yan-Way Quarter, Magway Township. All subjects were recruited by inclusion and exclusion criteria. Inclusion criteria was agricultural workers of age 18 - 45 years working in pesticide-used farms who involve in pesticide application process for at least one year for exposed group and apparently healthy subjects of age $18-45$ years who did not involve in pesticide application process for non-exposed group. Subjects with acute or chronic infection, being under any medication such as drugs affecting respiratory function, current smoker, current alcoholic and presence of known respiratory diseases, chest wall or spinal deformity and any intra-abdominal abnormalities were excluded. The detailed procedure was explained and written informed consent was taken. This study was approved by the Ethics Review Committee of the University of Medicine, Magway.

\section{Data Collection Method}

Data collection was done during pesticide spraying season. All subjects were requested to fast overnight (both solid and liquid) for ten hours. On the day of experiment, subjects were requested for arriving to the local administrator office at 6:00 am. On arrival, after taking ten minutes rest, Forced vital capacity (FVC) maneuver was done by using Spirodbank II spirometer. Then, six milliliters of venous blood sample was collected from antecubital vein under aseptic condition by using a disposable syringe and needle for each subject. Three milliliters of blood was kept in an ethylenediaminetetraacetic acid (EDTA) tube for packed cell separation and other three milliliters of blood was kept in plain tube and allowed to clot for thirty minutes at room temperature before centrifugation. All blood samples were transported to the Common Research Laboratory, University of Medicine, Magway using an effective cold chain system. Upon arrival, the blood in EDTA tube was centrifuged for fifteen minutes at $1000 \mathrm{rpm}$. The supernatant plasma and buffy coat were removed. Packed cells were washed three times with isotonic saline. Then, these were stored at $2^{\circ} \mathrm{C}$ until analysis. AChE activity was measured within three days. The blood in plain tube was centrifuged for fifteen minutes at $3000 \mathrm{rpm}$. Serum was separated and kept in screwtight bottle which was stored at $-20^{\circ} \mathrm{C}$ until analysis.

\section{Respiratory Function Test}

Respiratory function parameters were measured by using Spirobank II spirometer (910575, Medical International Research, Italy).

\section{Measurement of Erythrocyte Acetylcholinesterase (AChE) Activity}

Erythrocyte AChE activity was measured by Ellman's spectrophotometric method.

\section{Measurement of Serum Interleukin-6 Level}

Serum IL-6 levels were determined by enzyme-linked immunosorbent assay (IL-6 immunoassay, DRG Instruments, Germany).

\section{Statistical Analysis of Data}

Data entry and analysis were done by SPSS software (Statistical Package for Social Sciences) version 16 (IBM, Armonk, New York, United State of America). Erythrocyte AChE activity, serum IL-6 level and respiratory function test values were described as mean \pm SD. Comparisons were done by unpaired Student's $t$-test and Pearson's correlation was used to correlate between erythrocyte AChE activity, serum IL-6 level and respiratory function. Significant level was set at $p \leq 0.05$.

\section{RESULTS}

Table 1 shows the general characteristics of the subjects participated in this study. Mean erythrocyte AChE activity was significantly different between non-exposed and exposed group (Figure 1). Serum IL-6 level of exposed group was significantly higher than that of non-exposed group (Figure 2). Table 2 shows the percentage of predicted value of all respiratory function parameters such as forced expiratory volume in first second $\left(\mathrm{FEV}_{1}\right)$, forced vital capacity (FVC), ratio of forced expiratory volume in first second and forced vital capacity $\left(\mathrm{FEV}_{1} / \mathrm{FVC}\right)$, peak expiratory flow (PEF) and average forced expiratory flow between 25\% and $75 \%$ of FVC $\left(\mathrm{FEF}_{25-75 \%}\right)$ of non-exposed and exposed group. Table 3 shows the correlation between erythrocyte AChE activity and the percentage of predicted value of all respiratory function parameters. Among them, there was significant positive correlation between erythrocyte $\mathrm{AChE}$ activity and the percentage of predicted value of $\mathrm{FEV}_{1}$, FVC and PEF (Table 3). The significant negative correlation between erythrocyte AChE activity and serum IL-6 level is shown in Figure 3. Table 4 shows the correlation between serum IL-6 level and the percentage of predicted value of all respiratory function parameters. There was a significant negative correlation between serum IL-6 level and the percentage of predicted value of $\mathrm{FEV}_{1}$ and $\mathrm{FVC}$.

\section{DISCUSSION}

A total of eighty subjects (forty subjects for non-exposed group and forty subjects for exposed group) participated in the present study. Age 
Table 1: General characteristics of the subjects.

$\begin{array}{ccc}\text { Variable } & \begin{array}{c}\text { Non-exposed Group } \\ (n=40)\end{array} & \begin{array}{c}\text { Exposed Group } \\ (n=40)\end{array} \\ \text { Age (years) } & 40.40 \pm 2.59 & 40.45 \pm 3.14 \\ \text { Body Weight }(\mathrm{Kg}) & 59.50 \pm 3.87 & 55.97 \pm 7.67 \\ \text { Height }(\mathrm{m}) & 1.65 \pm 0.05 & 1.60 \pm 0.08 \\ \left.\text { BMI (Kg/m } \mathrm{m}^{2}\right) & 21.99 \pm 1.31 & 21.98 \pm 1.84 \\ \text { Duration of exposure } & - & 12.97 \pm 1.98 \\ \text { (years) } & & \end{array}$

Data expressed as mean \pm SD; BMI: Body mass index

Table 2: Comparison of respiratory function parameters between groups.

$\begin{array}{cccc}\begin{array}{c}\text { Respiratory Function } \\ \text { Parameters } \\ \text { (\% of predicted value) }\end{array} & \begin{array}{c}\text { Non-exposed } \\ \text { Group } \\ (n=40)\end{array} & \begin{array}{c}\text { Exposed Group } \\ (n=40)\end{array} & \begin{array}{c}\mathrm{p} \\ \text { value }\end{array} \\ \mathrm{FEV}_{1} & 75.95 \pm 4.05 & 72.13 \pm 4.40 & <0.05 \\ \mathrm{FVC} & 70.60 \pm 4.20 & 66.90 \pm 4.40 & <0.05 \\ \mathrm{FEV}_{1} / \mathrm{FVC} & 111.32 \pm 1.33 & 110.35 \pm 2.69 & <0.05 \\ \text { PEF } & 79.40 \pm 5.09 & 75.52 \pm 8.66 & <0.05 \\ \mathrm{FEF}_{25-75 \%} & 90.03 \pm 6.19 & 88.18 \pm 4.84 & >0.05\end{array}$

Statistical analysis was done by unpaired Student's $t$-test. $P<0.05$ was considered significant. $\mathrm{FEV}_{1}$ : Forced expiratory volume in first second; FVC: Forced vital capacity; $\mathrm{FEV}_{1} / \mathrm{FVC}$ : Ratio of forced expiratory volume in first second and forced vital capacity; PEF: Peak expiratory flow; $\mathrm{FEF}_{25-75 \%}$ : Average forced expiratory flow between $25 \%$ and $75 \%$ of FVC.

and BMI-matched male subjects were recruited in this study. Mean age ( $40.40 \pm 2.60$ vs $40.45 \pm 3.14$ years) and BMI $(21.99 \pm 1.31$ vs $21.99 \pm 1.84 \mathrm{~kg} /$ $\mathrm{m}^{2}$ ) were not significantly different between non-exposed and exposed group.

In the present study, the mean duration of pesticide exposure of exposed group was $12.97 \pm 1.98$ years. It indicates that there has chronic exposure of OP pesticides. According to the result of the present study, there has a significant decrease in the erythrocyte AChE activity in agricultural workers who exposed to OP pesticides compared to the non-exposed group. The result of present study is in accordance with previous studies done by Gomes et al. (1997), Ogut et al. (2011), Dutta et al. (2019), Manyilizu et al. (2016) and Mya-Pwint-Phyu et al. (2020). ${ }^{[14-18]}$

On the other hand, this result is not coinciding with the finding of study done by Shadnia et al. 2005. ${ }^{[19]}$ This inconsistency may be due to the differences in amount of dosage or duration of exposure. OP compounds are AChE inhibitors by using phosphorylation of the serine hydroxyl group located at the active site of the enzyme. These compounds inhibit the actions of both AChE in red blood cell and serum AChE enzymes. Among them, serum AChE activity is more decreased than erythrocyte AChE activity after OP pesticide exposure. Therefore erythrocyte AChE activity is an indicator of chronic pesticide exposure and so the measurement of erythrocyte AChE activity is recognized as a human biological marker of OP pesticides exposure. ${ }^{[20,21]}$

Among the inflammatory markers, interleukin-6 is the major inflammatory mediator which has both pro- inflammatory and antiinflammatory effects. IL-6 is a keystone cytokine in health and disease. Natural human IL-6 is a single polypeptide chain of 185 amino acids. In humans, this protein is encoded by the IL- 6 gene. ${ }^{[22]}$ In the present study,
Table 3: Correlation between erythrocyte acetyl cholinesterase enzyme activity and respiratory function parameters in non-exposed and exposed group.

$\begin{array}{ccc}\begin{array}{c}\text { Respiratory Function } \\ \text { Parameters } \\ \text { (\% of predicted value) }\end{array} & \begin{array}{c}\text { Erythrocyte AchE activity } \\ (\mathrm{U} / \mathrm{L})\end{array} & \text { p value } \\ \mathrm{FEV}_{1} & \mathrm{r}=0.425 & \\ \mathrm{FVC} & \mathrm{r}=0.301 & <0.001 \\ \mathrm{FEV}_{1} / \mathrm{FVC} & \mathrm{r}=0.099 & <0.05 \\ \mathrm{PEF} & \mathrm{r}=0.316 & >0.05 \\ \mathrm{FEF}_{25-75 \%} & \mathrm{r}=0.098 & <0.05 \\ & >0.05\end{array}$

$\mathrm{FEV}_{1}$ : Forced expiratory volume in first second; FVC: Forced vital capacity; FEV $/$ /FVC: Ratio of forced expiratory volume in first second and forced vital capacity; PEF: Peak expiratory flow; $\mathrm{FEF}_{25-75 \%}$ : Average forced expiratory flow between $25 \%$ and $75 \%$ of FVC; r: Pearson's correlation coefficient.

Table 4: Correlation between serum interleukin- 6 level and respiratory function Parameters in non-exposed and exposed group.

$\begin{array}{ccc}\begin{array}{c}\text { Respiratory Function } \\ \text { Parameters } \\ \text { (\% of predicted value) }\end{array} & \begin{array}{c}\text { Serum IL-6 Level } \\ (\mathbf{p g} / \mathbf{m L})\end{array} & \text { p value } \\ \mathrm{FEV}_{1} & \mathbf{r}=-\mathbf{0 . 3 0 0} & <0.05 \\ \mathrm{FVC} & \mathrm{r}=-0.331 & <0.05 \\ \mathrm{FEV}_{1} / \mathrm{FVC} & \mathrm{r}=-0.186 & >0.05 \\ \mathrm{PEF} & \mathbf{r}=\mathbf{- 0 . 1 9 4} & >\mathbf{0 . 0 5} \\ \mathrm{FEF}_{25-75 \%} & \mathbf{r}=\mathbf{- 0 . 1 0 4} & >\mathbf{0 . 0 5}\end{array}$

$\mathrm{FEV}_{1}$ : Forced expiratory volume in first second; FVC: Forced vital capacity; $\mathrm{FEV}_{1}$ /FVC: Ratio of forced expiratory volume in first second and forced vital capacity; PEF: Peak expiratory flow; $\mathrm{FEF}_{25-75 \%}$ : Average forced expiratory flow between $25 \%$ and $75 \%$ of FVC; r: Pearson's correlation coefficient.

serum IL-6 level was significantly higher in exposed group than nonexposed group. Furthermore, there was a significant negative correlation between erythrocyte AChE enzyme activity and serum IL-6 level ( $\mathrm{r}=$ $-0.374, n=80, p<0.05$ ). These results have strengthened the hypothesis that $\mathrm{OP}$ pesticides can affect the immune system and inflammatory markers.

A study done by Alluwaimi and Hussein reported that the immunotoxicity caused by OP pesticides lead to increased levels of inflammatory markers in mice. Therefore, the finding of the present study was consistent with those reported by Alluwaimi and Hussein. ${ }^{[23]}$ In another study done by Taghavian et al. (2016), there was no significant difference of serum IL-6 level in exposed group and non-exposed group to OP pesticides. But serum IL-6 level was significantly difference in female exposed group and female non-exposed group to OP pesticides. ${ }^{[2]}$

Occupational exposure to pesticides gives adverse effects on the respiratory system. Many epidemiological studies reported that there are many respiratory diseases after chronic exposure of pesticides such as asthma, chronic bronchitis and lung cancer. ${ }^{[25-27]}$ Moreover, many cross-sectional and prospective cohort studies reported that there is a significant decrease in the lung function parameters in agricultural workers comparing with non-exposed subjects. ${ }^{[8-11,28]}$

In the present study, the percentage of predicted value of respiratory function parameters $\left(\mathrm{FEV}_{1}, \mathrm{FVC}, \mathrm{FEV}_{1} / \mathrm{FVC}\right.$ and $\left.\mathrm{PEF}\right)$ was significantly reduced in exposed group when compared with the non-exposed group. 


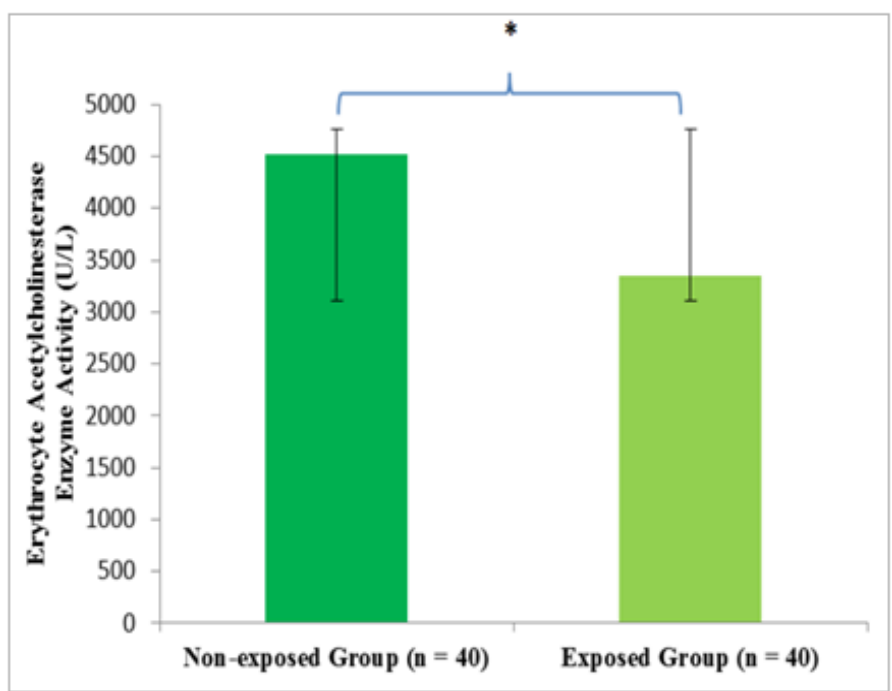

Figure 1: Comparison of erythrocyte acetylcholinesterase enzyme activity between non-exposed and exposed group.

Comparison was done by unpaired Student's t-test

* indicates significant difference between two groups $p<0.05$

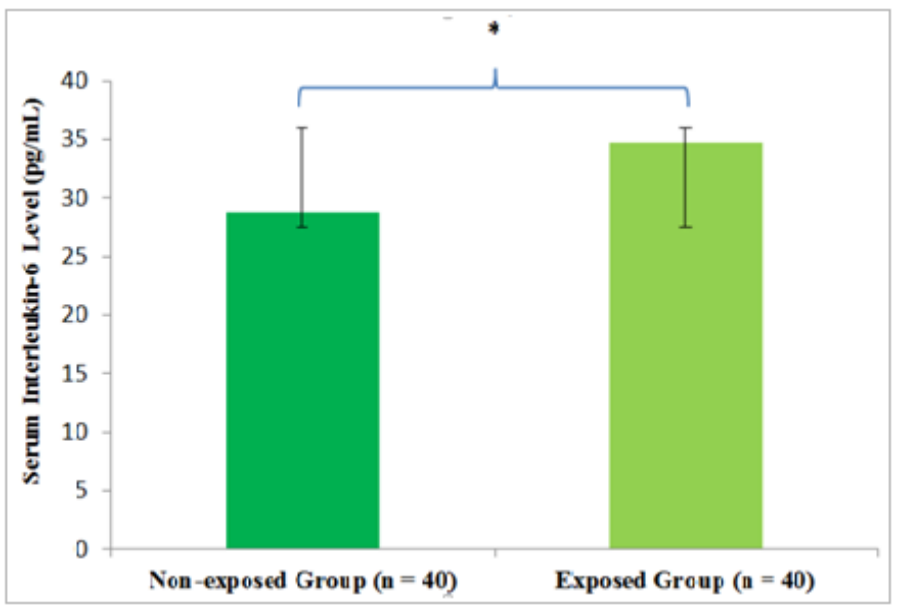

Figure 2: Comparison of serum interleukin- 6 level between non-exposed and exposed group.

Comparison was done by unpaired Student's $t$-test

* indicates significant difference between two groups $p<0.05$

When comparisons in the respiratory function parameters were done, the observed values were converted to the percentage of the predicted values to avoid the confounding effects of age, height and ethnic group. The same protocol according to ATS/ERS guidelines was applied to all subjects of the present study to obtain accurate and precise measurement. Changes in $\mathrm{FEV}_{1}$ and $\mathrm{FEV}_{1} / \mathrm{FVC}$ ratio are predominantly related to large airways and $\mathrm{PEF}$ and $\mathrm{FEF}_{25-75 \%}$ alterations are related to small airways. ${ }^{[2]}$ Previous studies investigated the respiratory function of OP pesticideexposed agricultural workers and found a significant decrease in the FVC, FEV $, \mathrm{FEV}_{1} / \mathrm{FVC}, \mathrm{PEF}$ and $\mathrm{FEF}_{25-75 \%}{ }^{[8-11,28]}$ These studies showed that there was association between respiratory function impairments and occupational exposure to pesticides, independent of smoking.

In the present study, there was a significant positive correlation between erythrocyte AChE enzyme activity and respiratory function parameters such as $\mathrm{FEV}_{1}(\mathrm{r}=0.425, n=80, p<0.001)$; FVC $(\mathrm{r}=0.301, n=80, p$

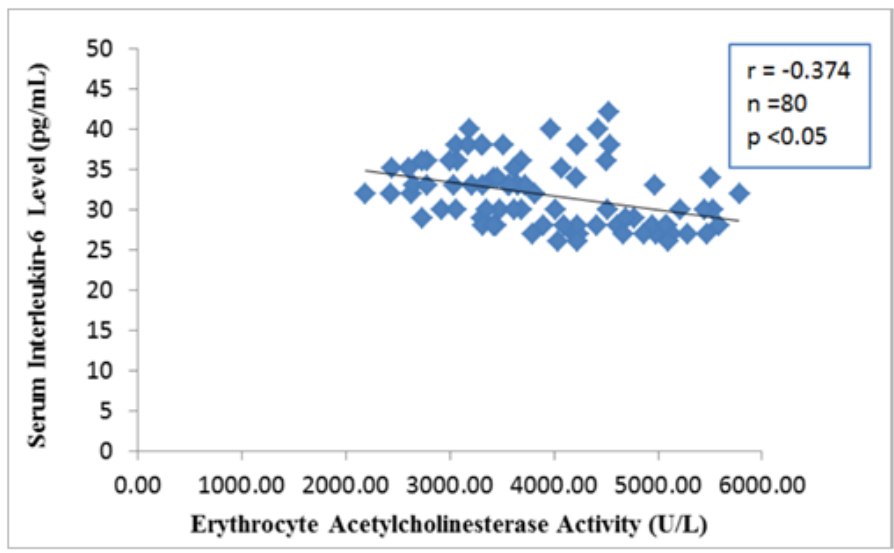

Figure 3: Correlation between erythrocyte acetylcholinesterase activity and serum interleukin-6 level.

Correlation was done by using Pearson's correlation test

$r$ : Pearson's correlation coefficient; $n=$ Total number of subjects

$<0.05)$ and PEF $(r=0.316, n=80, p<0.05)$. Furthermore, there was a significant negative correlation between serum IL-6 level and respiratory function parameters such as $\mathrm{FEV}_{1}(\mathrm{r}=0.300, n=80, p<0.05)$ and FVC $(\mathrm{r}=0.331, n=80, p<0.05)$. The present findings provide the evidences of the chronic effects of pesticide exposure on respiratory health and possibly the development of chronic lung diseases.

Although the role of inflammation and the cytokines play in the respiratory function impairment is poorly understood, some studies have been reported that there was association between serum IL-6 level and respiratory function decline in apparently healthy subjects and patients who suffer asthma and COPD. ${ }^{[30,31]}$

During OP pesticide poisoning, cytokines such as IL-6 and TNFa secretion are increased. These cytokines also encourage inflammatory state and may act via systemic inflammation to negatively affect respiratory function. There have many possible causes of relationship between increased serum IL- 6 and respiratory function decline. IL-6 binds to IL-6 receptor which situated on the bronchial epithelial cells and cause increased secretion of mucous. Mucous hypersecretion can contribute to respiratory function decline. ${ }^{[32]}$

\section{CONCLUSION}

In the present study, the percentage of predicted value of respiratory function parameters $\left(\mathrm{FEV}_{1}, \mathrm{FVC}, \mathrm{FEV}_{1} / \mathrm{FVC}\right.$ and $\left.\mathrm{PEF}\right)$ was significantly reduced in agricultural workers who exposed to OP when compared with the non-exposed group. Moreover, there was a significant positive correlation between erythrocyte AChE enzyme activity and respiratory function parameters such as $\mathrm{FEV}_{1}$, FVC and PEF. Furthermore, there was a significant negative correlation between serum IL-6 level and respiratory function parameters such as $\mathrm{FEV}_{1}$ and FVC. Therefore, it can be concluded that there has an impact of chronic low dose OP exposure on respiratory health and there has a role of IL-6 in respiratory function decline due to OP pesticide exposure.

\section{ACKNOWLEDGEMENT}

We would like to thank Department of Medical Research (DMR) External Grant Committee, Ministry of Health and Sport, The Republic of Union of Myanmar for awarding research funding. We are also very grateful to Professor Aye Aye Oo, Pro-rector, University of Medicine, Magway for sampling method and data analysis. We wish to record my 
deep sense of thanks to the participants from Magway Township who willingly gave consent to this study.

\section{Financial support and sponsorship}

Financial support was given by Department of Medical Research (DMR) External Grant (Grant No: 114/2019), Ministry of Health and Sport, The Republic of Union of Myanmar.

\section{CONFLICT OF INTEREST}

Authors declare that there are no conflicts of interest.

\section{ABBREVIATIONS}

OP: Organophosphate Compounds; AchE: Acetylcholine Esterase; Ach: Acetylcholine; ROS: Reactive Oxygen Species; RNS: Reactive Nitrogen Species; IL-6: Interleukin-6; CRP: C-reactive protein; BMI: Body Mass Index; FEV $_{1}$ : Forced Expiratory Volume in First Second; FVC: Forced Vital Capacity; FEV $/$ FVC: Ratio of Forced Expiratory Volume in First Second And Forced Vital Capacity; PEF: Peak Expiratory Flow; FEF $_{25-}$ ${ }_{75 \%}$ : Average Forced Expiratory Flow between 25\% and 75\% of FVC.

\section{REFERENCES}

1. Kapka-Skrzypczak L, Cyranka M, Skrzypczak M, Kruszewski M. Biomonitoring and biomarkers of organophosphate pesticides exposure-state of the art. Ann Agric Environ Med. 2011;18(2)294-303.

2. Fukuto TR. The chemistry of organic insecticides. Ann Rev Entomol. 1961;6(1):313-32.

3. Abdollahi M, Mostafalou S, Pournourmohammadi S, Shadnia S. Oxidative stress and cholinesterase inhibition in saliva and plasma of rats following subchronic exposure to malathion. Comp Biochem Physiol C Toxicol Pharmacol. 2004;137(1):29-34

4. Agrawal A, Sharma B. Pesticides induced oxidative stress in mammalian systems. Int J Biol Med Res. 2010;1(3):90-104.

5. Mostafalou S, Abdollahi M. Pesticides and human chronic diseases: evidences, mechanisms and perspectives. Toxicol Appl Pharmacol. 2013;268(2):157-77.

6. Jayaraj R, Megha P, Sreedev P. Organochlorine pesticides, their toxic effects on living organisms and their fate in the environment. Interdiscip Toxicol. 2016;9(34):90-100.

7. Deschamps D, Questel F, Baud FJ, Gervais P, Dally S. Persistent asthma after acute inhalation of organophosphate insecticide. Lancet. 1994;344(8938):1712.

8. Mekonnen Y, Agonafir T. Lung function and respiratory symptoms of pesticide sprayers in state farms of Ethiopia. Ethiop Med J. 2004;42(4):261-6.

9. Hernández AF, Casado I, Pena G, Gil F, Villanueva E, Pla A. Low level of exposure to pesticides leads to lung dysfunction in occupationally exposed subjects. Inhal Toxicol. 2008;20(9):839-49.

10. Chakraborty S, Mukherjee S, Roychoudhury S, Siddique S, Lahiri T, Ray MR. Chronic exposures to cholinesterase-inhibiting pesticides adversely affect respiratory health of agricultural workers in India. J Occu Health. 2009;51(6):488-97.

11. Cha ES, Lee YK, Moon EK, Kim YB, Lee YJ, Jeong WC, et al. Paraquat application and respiratory health effects among South Korean farmers. Occup Environ Med. 2012;69(6):398-403.

12. Gangemi S, Miozzi E, Teodoro M, Briguglio G, DeLuca A, Alibrando C. Occupational exposure to pesticides as a possible risk factor for the development of chronic diseases in humans. Mol Med Rep. 2016;14(5):4475-88.

13. Shaaban R, Kony S, Driss F, Leynaert B, Soussan D, Pin I, et al. Change in Creactive protein levels and FEV1 decline: A longitudinal population-based study. Respir Med. 2006;100(12):2112-20.

14. Gomes J, Lloyd O, Revitt DM, Norman JN. Erythrocyte cholinesterase activity levels in desert farm workers. Occu Med. 1997;47(2):90-4.

15. Ogut S, Gultekin F, Kisioglu AN, Kucukoner E. Oxidative stress in the blood of farm workers following intensive pesticide exposure. Toxicol Ind Health. 2011;27(9):820-5.

16. Manyilizu WB, Mdegela $\mathrm{RH}$, Kazwala $\mathrm{R}$, Nonga $\mathrm{H}$, Muller M, Lie E, et al. Association of long-term pesticide exposure and biologic parameters in female farm workers in Tanzania: A cross sectional study. Toxics. 2016;4(4):25.

17. Dutta S, Bahadur M. Effect of pesticide exposure on the cholinesterase activity of the occupationally exposed tea garden workers of northern part of West Bengal, India. Biomarkers. 2019;24(4):317-24.

18. Phyu MP, Hlaing ZT, Zaw T, Htway SM Sein MT. Correlation Study Between Erythrocyte Acetylcholinesterase Activity, Serum Malondialdehydeand Insulin Sensitivity in Agricultural Workers and Non-agricultural Workers in Nat-Kan Village, Magway Township. J Asean Fed Endocr Soc. 2020;35(1):85-92.

19. Shadnia S, Azizi E, Hosseini R, Khoei S, Fouladdel S, Pajoumand A. Evaluation of oxidative stress and genotoxicity in organophosphorus insecticide formulators. Hum Exp Toxicol. 2005;24(9):439-45.

20. Ohayo-Mitoko GJ, Kromhout H, Simwa JM, Boleij JS, Heederik D. Self-reported symptoms and inhibition of acetylcholinesterase activity among Kenyan agricultural workers. Occu Environ Med. 2000;57(3):195-200.

21. Ranjbar A, Pasalar P, Abdollahi M. Induction of oxidative stress and acetylcholinesterase inhibition in organophosphorous pesticide manufacturing workers. Hum Exp Toxicol. 2002;21(4):179-82.

22. Shegal PB, Zilberstein A, Ruggieri R, May LT, Ferguson-Smith A, Slate DL. Human chromosome 7 carries the beta 2 interferron gene. Proc Nat Aca Sci USA. 1986;83(14):5219-22.

23. Alluwaimi AM, Hussein Y. Diazinon immunotoxicity in mice: Modulation of cytokines level and their gene expression. Toxicology. 2007;236(1-2):123-31.

24. Taghavian F, Vaezi G, Abdollahi M, Malekirad AA. Comparative toxicological study between exposed and non-exposed farmers to organophosphorus pesticides. Cell J. 2016;18(1):89.

25. Salameh P, Waked M, Baldi I, Brochard P, Abi SB. Respiratory diseases and pesticide exposure: A case-non-exposed study in Lebanon. J Epidemiol Commun Health. 2006;60(3):256-61

26. Mostafalou S, Abdollahi M. Pesticides: An update of human exposure and toxicity. Arc Toxicol. 2017;91(2):549-99.

27. Hoppin JA, Valcin M, Henneberger PK, Kullman GJ, Umbach DM, London SJ, et al. Pesticide use and chronic bronchitis among farmers in the Agricultural Health Study. Am J Ind Med. 2007;50(12):969-79.

28. Zuskin E, Mustajbegovic J, Schachter EN, Kern J, Deckovic-Vukres V Trosic I, et al. Respiratory function in pesticide workers. J Occu Environ Med. 2008;50(11):1299-305.

29. DeJong K, Marike BH, Kromhout H, Vermeulen R, Vonk JM, Postma DS, et al. Occupational exposure to vapors, gases, dusts and fumes is associated with small airways obstruction. Am J Respir Critic Care Med. 2014;189(4):487-90.

30. Rasmussen F, Mikkelsen D, Hancox RJ, Lambrechtsen J, Nybo M, Hansen HS, et al. Inflammatory markers are associated with reduced lung function in young adults. Eur Respir J. 2009;33:382-8.

31. Gimeno D, Delclos GL, Ferrire JE, Bull AR. Association of CRP and IL-6 with lung function in a middle-aged population initially free from self-reported respiratory problems: the Whitehall II study. Eur J Epidemiol. 2011;26(2):135-44.

32. Neveu WA, Allard JL, Dienz O, Matthew JW, Gennaro C, Laurie AW, et al. IL-6 is required for airway mucous production induced by inhaled fungal allergens. J Immunol. 2009;10:1731-8. 